\title{
Zinc Oxide Thin Film \\ Prepared by Micro-Dropping Chemical Method on QCM for Gas Sensing
}

\author{
Y. BAKHA* AND H. KHALES
}

DMN, Centre de Développement des Technologies Avancées, cité du 20 août 1956 Baba Hassen, Algiers, Algeria

(Received May 13, 2019; revised version June 11, 2019; in final form September 12, 2019)

The paper presents fabrication and characterization of $\mathrm{ZnO}$ coated on a quartz crystal microbalance for gas sensing at room temperature. The $\mathrm{ZnO}$ thin films were chemically deposited as sensitive layer on the top of the QCM by micro-dropping technique. The morphology of the coated thin film was examined by scanning electron microscopy and X-ray diffraction in order to analyze the crystalline nature of the structure. The $\mathrm{ZnO}$ coated on a quartz crystal microbalance sensor showed a good sensitivity to the gases tested: ethanol, acetone, and humidity. High sensitivity was obtained for ethanol vapor more than acetone, with good reproducibility and stability of the sensor when exposed to different concentrations given respectively 50, 100, $200 \mathrm{ppm}$. The influence of humidity was examined under different relative humidity. The results indicate that the $\mathrm{ZnO}$ coated on a QCM shows a high response and fast response/recovery characteristics under humidity comparing to ethanol and acetone vapor.

DOI: 10.12693/APhysPolA.136.490

PACS/topics: micro-dropping deposition, zinc oxide, gas sensor, quartz crystal microbalance

\section{Introduction}

The use of chemical sensor is dramatically increasing and covering a wide range spectrum of sensing applications for various fields, particularly, environmental and industrial control, medical diagnostic, agriculture, and public security.

Recently, quartz crystal microbalances (QCM) have attracted considerable research interest due to their high response and sensitivity [1-3]. The operating principle work of QCM sensor is based on the change of resonance frequency due to mass change caused by the adsorption phenomena related to the sensitive layer [4]. Different metal oxide materials can be used as sensitive layer. These materials contain $\mathrm{ZnO}[5-8], \mathrm{SnO}_{2}$ [9], $\mathrm{TiO}_{2}$ [1, 10-12], $\mathrm{In}_{2} \mathrm{O}_{3}$, and CdS [13]. This materials are chosen for their excellent sensing properties such us high response, good stability, and their sensibility for volatile vapor and humidity.

Actually, researchers are focused on realization of QCM gas sensor using low cost method for deposition of coating film such as spray pyrolysis [14, 15], chemical bath deposition (CBD) technique [16], and droplet inject technique [17]. Many studies demonstrate that the $\mathrm{ZnO}$ metal oxide is one of most important and preferred materials used for gas sensing as humidity and volatile vapor $[5-8,18,19]$. With this purpose we investigate the $\mathrm{ZnO}$ deposition by micro-dropping deposition, which can permit local deposition in ambient air of thin films on the surface of QCM electrode without destroying or damaging the piezoelectric quartz. The present work is

*corresponding author; e-mail: ybakha@cdta.dz to employ a $\mathrm{ZnO}$ thin film as the sensitive layer coated on a commercial QCM to monitor, at room temperature, the adsorption of ethanol, acetone, and humidity. The sensitive layer is grown by the chemical dropping technique. The as-coated QCM was positioned in the test chamber before the admission of the gases to be detected.

\section{Experimental}

$\mathrm{ZnO}$ sensitive layer was synthesized by dropping chemical method. The aqueous solution was prepared using zinc acetate dehydrated $\left(\mathrm{Zn}\left(\mathrm{CH}_{3} \mathrm{COO}\right)_{2} \cdot 2 \mathrm{H}_{2} \mathrm{O}\right)$ (99.99\%) dissolved in methanol $\left(\mathrm{CH}_{3} \mathrm{OH}, 99.99 \%\right)$ on a commercial quartz-crystal microbalance, with $0.1 \mathrm{M}$ concentration. The solution was dropped on to the electrode of $\mathrm{QCM}$ at $T=350^{\circ} \mathrm{C}$. Figure 1 shows the process of $\mathrm{ZnO}$ thin film based gas sensor fabrication.

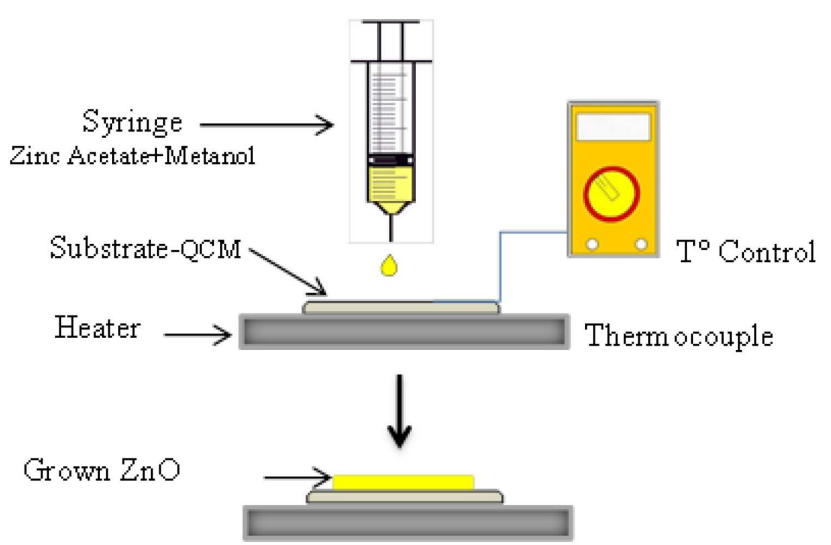

Fig. 1. Process of $\mathrm{ZnO}$ thin film based gas sensor fabrication. 
Gas sensing measurement of the QCM coated with $\mathrm{ZnO}$ was conducted using a gas sensing system, as shown in Fig. 2. The vapor sample was carried to the chamber test and extracted by the injection of the ambient air with N810FT.18 vacuum pump. Inside the chamber, the humidity and temperature evolution was monitored by AM2301 temperature and humidity sensor with Arduino microcontroller. Then, the frequency response of $\mathrm{ZnO}$ coated on QCM was measured using transistor Colpitts oscillator connected to the frequency counter TF930 TTi, and the measurements were displayed on a PC.

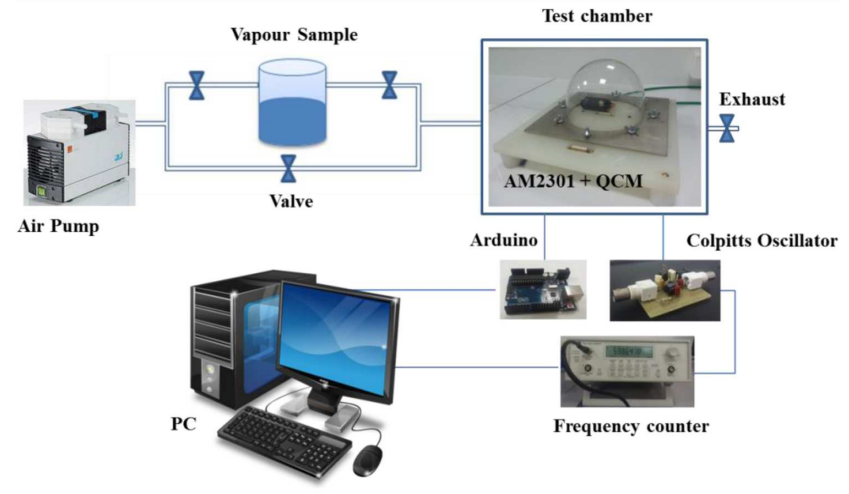

Fig. 2. Gas sensing measurement setup.

The surface morphology of the $\mathrm{ZnO}$ film coated on QCM was observed with scanning electronic microscopy (SEM) using SEM-JEOL 6400. The crystalline and crystal phases of as prepared sample were determined by $\mathrm{X}$-ray diffraction (XRD Bruker D8), with the Bragg angle ranging in 20-8 deg. Gas testing was carried out by frequency measurements of the Colpitts oscillator with QCM coated with $\mathrm{ZnO}$ to record the response of our gas sensor under different environment.

\section{Result and discussion}

Figure 3 shows a photograph as fabricated device and SEM image of top view of $\mathrm{ZnO}$ thin film coated on QCM type HC49U as obtained. It can be seen that QCM wafer was covered by small sized particle.

In order to observe the properties of the coated material, we performed the XRD pattern of QCM $6 \mathrm{MHz}$ type $\mathrm{HC} 49 \mathrm{U}$ and the $\mathrm{ZnO}$ thin film coated on QCM as shown in Fig. 4.

Figure 4a represents the XRD pattern of the QCM without $\mathrm{ZnO}$ thin films. The diffraction peaks arise at (111) $38.39^{\circ},(200) 44.47^{\circ},(220) 64.61^{\circ}$, (311) $77.58^{\circ}$, and (222) $81.74^{\circ}$ planes, respectively, corresponding to silver material by comparing with the standard JCPDS data Ag (JCPDS Card No. 89-3722).

Figure $4 \mathrm{~b}$ represents the XRD pattern of $\mathrm{ZnO}$ thin film coated on QCM. The peak position agrees well with the reflections of hexagonal structure of $\mathrm{ZnO}$ (JCPDS Card No. 36-1451). The diffraction peaks arise at (100) $31.75^{\circ}$,
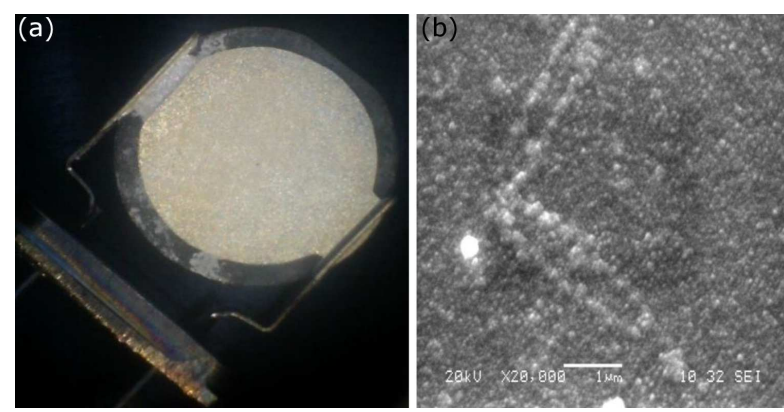

Fig. 3. $\mathrm{ZnO}$ thin film coated on QCM as obtained (a) photograph as fabricated device, (b) SEM image of ZnO thin film deposited on QCM substrate.
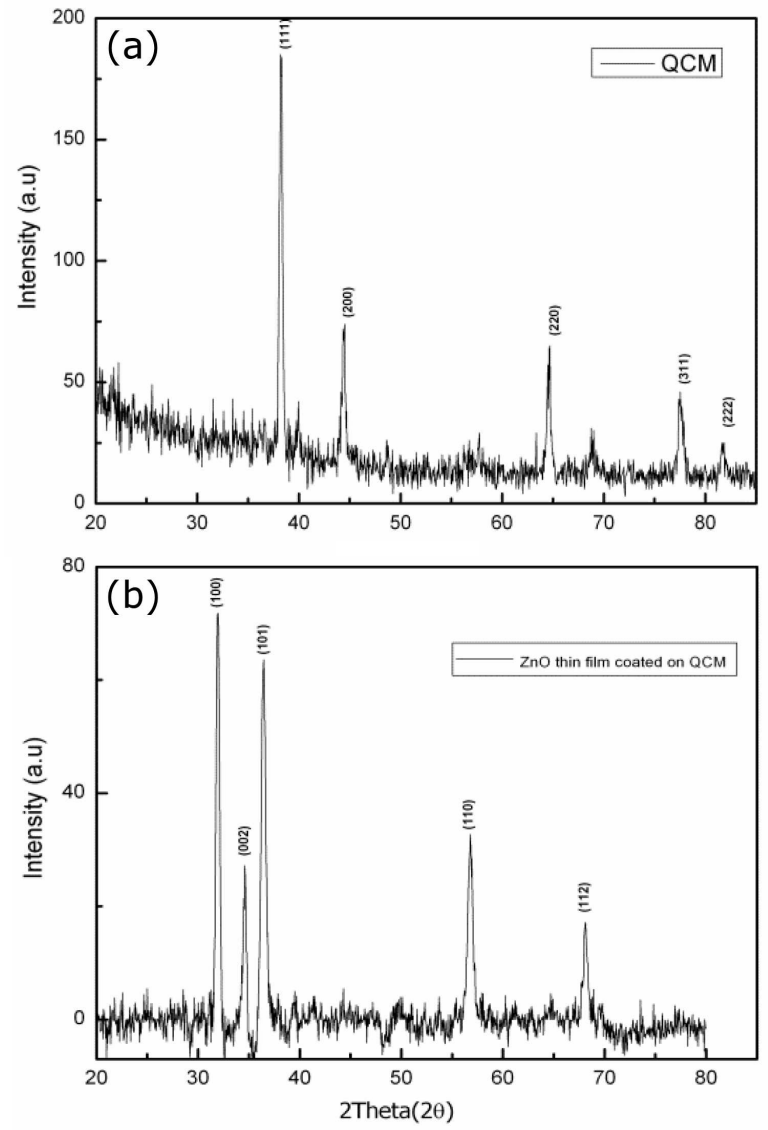

Fig. 4. XRD patterns of (a) QCM, (b) $\mathrm{ZnO}$ thin film coated on QCM deposited at $350^{\circ}$.

(002) $34.62^{\circ},(101) 36.14^{\circ}$, (110) $56.62^{\circ}$ and (112) $67.88^{\circ}$. We can clearly see that the preferential orientation of $\mathrm{ZnO}$ thin film coated on QCM is (100). The diffraction peaks can be well indexed to pure hexagonal phase $\mathrm{ZnO}$.

The crystallite size of the thin films was determined using the Scherrer formula [20]:

$$
D=\frac{K \lambda}{\beta \cos \theta_{(h k l)}},
$$


where $K=0.9, D$ is the crystallite size, $\lambda=0.1540 \mathrm{~nm}$ is the mean wavelength of $\mathrm{Cu} K_{\alpha}$ radiation, and $\beta$ is the full-width at half maximum (FWHM) of the Bragg peak observed at the Bragg angle $\theta(\mathrm{rad})$. The grain sizes calculated are found to be $\approx 20 \mathrm{~nm}$.

The lattice constants $a$ and $c$ for the $\mathrm{ZnO}$ deposited film were calculated using equations (Lupan et al., 2010) [21]:

$$
d_{h k l}=\frac{a}{\sqrt{\frac{4}{3}\left(h^{2}+k^{2}+h k\right)+\left(l \frac{a}{c}\right)^{2}}} .
$$

The calculated lattice parameters are given respectively $a=3.232 \AA$ and $c=5.177 \AA$. The lattice parameters of $\mathrm{ZnO}$ thin films coated on QCM are characteristic of a hexagonal unit which agree well with literature reported in JCPDS standard data $a=3.24982 \AA$ and $c=5.20661 \AA[22]$. The ratio $a / c=0.620$ for the $\mathrm{ZnO}$ thin films.

Figure 5 shows the response transients of $\mathrm{ZnO}$ coated QCM sensor to switching-on and off, of the ethanol and acetone gas with $200 \mathrm{ppm}$ concentration at room temperature $\left(25^{\circ} \mathrm{C}\right)$. At first the sensor was measured under air. The sensor then was exposed to different gas.
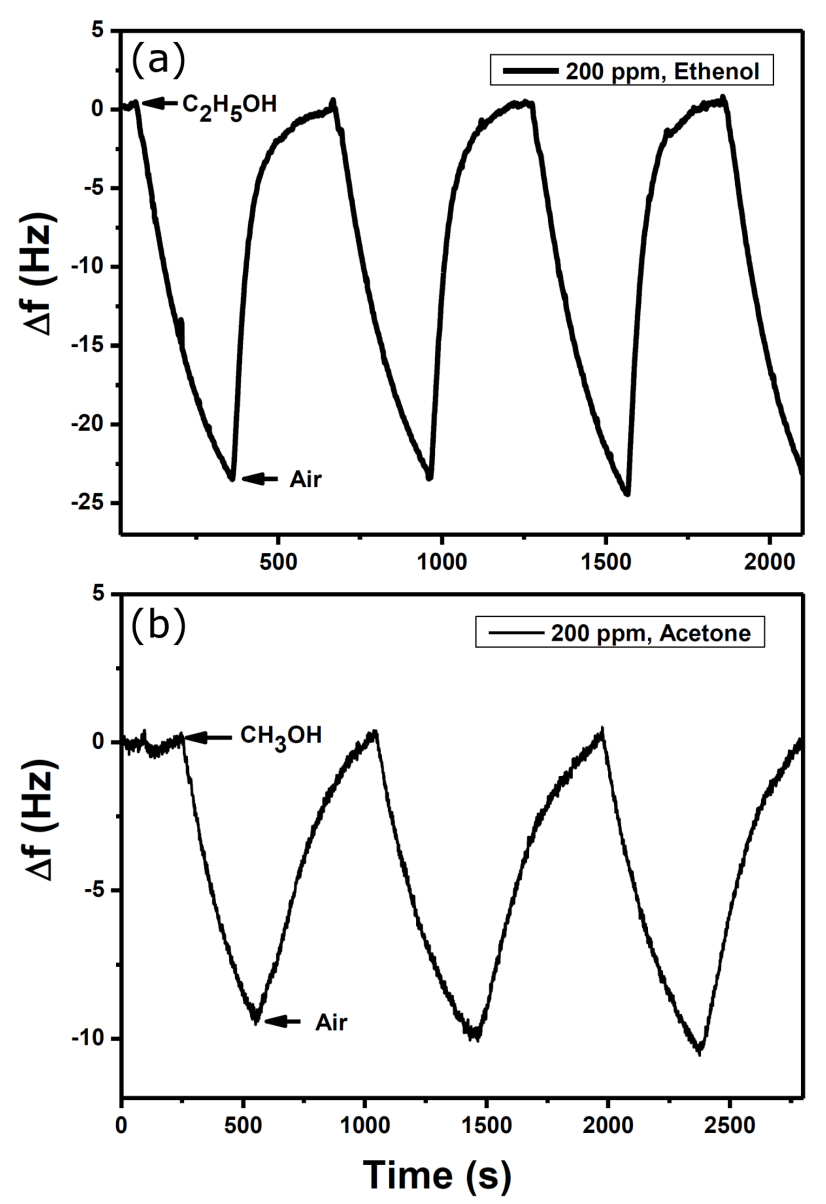

Fig. 5. Response of the fabricated sensor to $200 \mathrm{ppm}$ of: (a) ethanol, (b) acetone concentrations.
The change of resonance frequency of QCM $(\Delta f)$ can be directly related to change in mass $(\Delta m)$ due to the adsorption phenomena of $\mathrm{C}_{2} \mathrm{H}_{5} \mathrm{OH}$ and $\mathrm{CH}_{3} \mathrm{OH}$ gas molecules on $\mathrm{ZnO}$ thin films using the Sauerbrey equation $[18,19]$ :

$$
\Delta f=\frac{-2 f_{0}^{2}}{A \sqrt{\rho_{q} \nu_{q}}} \Delta m,
$$

where $A$ is the active area of QCM electrode in $\mathrm{cm}^{2}, f_{0}$ is the resonance frequency of the $\mathrm{QCM}$ in hertz $(\mathrm{Hz}), \Delta m$ is the change in oscillating mass in $\mathrm{g}, \rho_{q}$ is the density of quartz, and $\nu_{q}$ is the shear velocity in the quartz.

The response time is the time required to reach $90 \%$ of the final value in the shift change of the quartz resonance frequency and the recovery time is time required to reach $90 \%$ desorption, which are respectively (225 and $252 \mathrm{~s}$ ), (322 and $350 \mathrm{~s}$ ) for ethanol and acetone. We can clearly see that ethanol time response is faster than acetone gas response time.

In order to see the reproducibility and reversibility of the response of our sensor under ethanol we have used different concentrations. For all three concentrations, the shape of the kinetics of the response recorded on the sensor studied is similar to that reported in the literature for gas sensors [5], as illustrated in the signals gas response of Fig. 5. It can be noted that the sensor exhibits good reversibility because the QCM restores its initial oscillation frequency after an absorption and desorption cycle. Restoring the initial crystal frequency offset indicates complete desorption of the sensor, indicating that no chemical bond was formed during the adsorption process. Note also the presence of an asymmetry of the response in the adsorption and desorption cycle. The traditional interpretation of this asymmetry is based on slower kinetics for the volatile compounds for which desorption needs heat power to accelerate the phenomena of desorption from the coating film [23, 24].

Figure $6 \mathrm{a}$ shows the response of the sensor under 50, 100 , and $200 \mathrm{ppm}$ concentration of $\mathrm{C}_{2} \mathrm{H}_{5} \mathrm{OH}$. We can see clearly that sensor had the same response for the three concentrations with different frequency shift. The responses indicate that the sensor had good reproducibility. It is obvious that the frequency shift linearly increases with an increase in the ethanol gas concentration in the range of $50-200 \mathrm{ppm}$. This indicates that more ethanol molecules are adsorbed on the $\mathrm{ZnO}$ thin film with the increase in the ethanol gas concentration. It can be seen in Fig. $6 \mathrm{~b}$ that the response time is shorter than the recovery time. The response and recovery times are of the order of 202 and 220 s, 213 and $230 \mathrm{~s}, 225$ and $252 \mathrm{~s}$, for the three concentrations, respectively 50, 100, $200 \mathrm{ppm}$.

The presence of $\mathrm{H}_{2} \mathrm{O}$ molecule in ambient air could have effect of response of $\mathrm{ZnO}$ as sensitive layer [18]. In order to see the effect of humidity on our sensor we have used different Relative humidity $(\mathrm{RH})$. Figure 7 shows time dependent changes on the frequency of $\mathrm{ZnO}$ coated QCM sensor upon successive exposure cycles of $50 \% \mathrm{RH}$ 

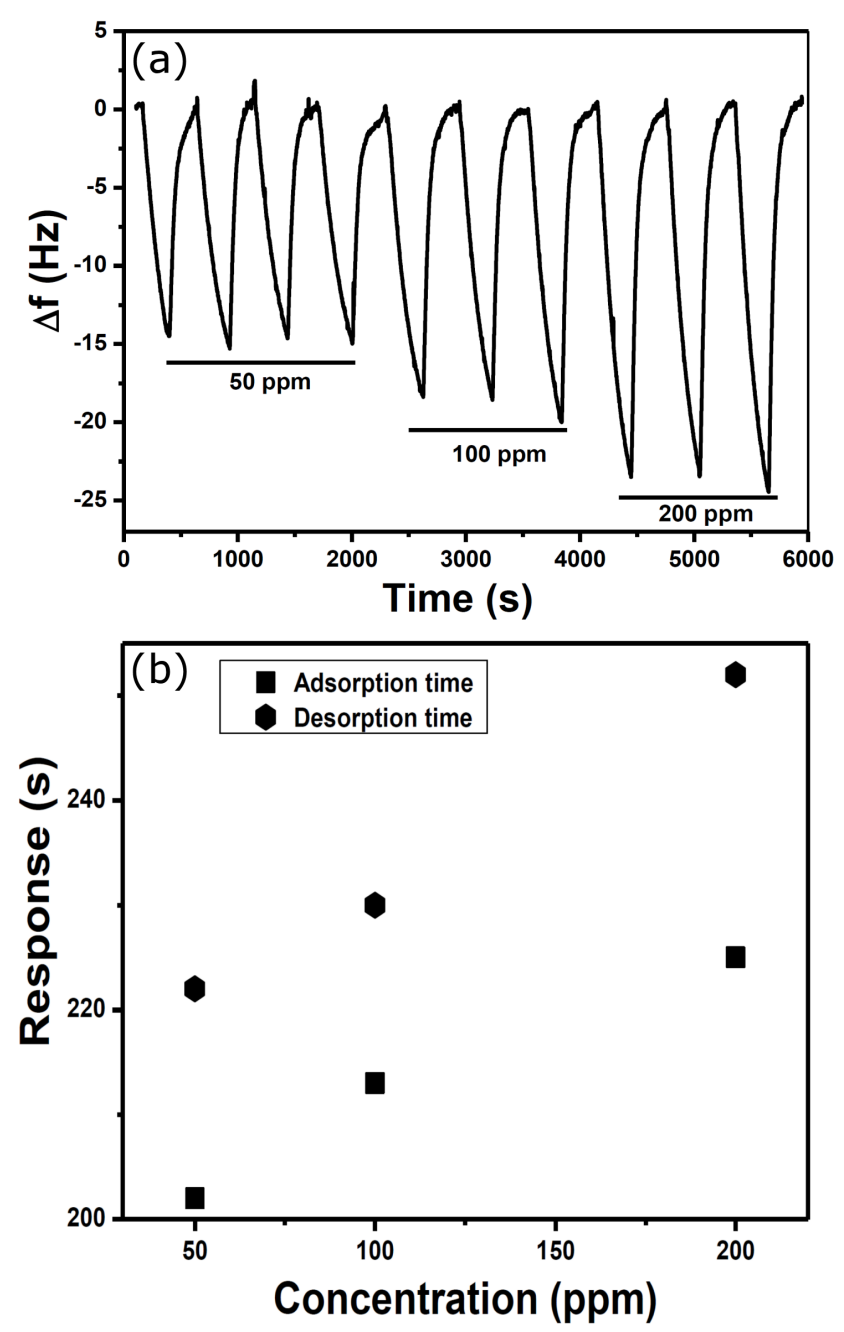

Fig. 6. ZnO QCM sensor response under ethanol test: (a) reproducibility measurements and (b) shows the response and recovery times under: 50, 100 and $200 \mathrm{ppm}$.

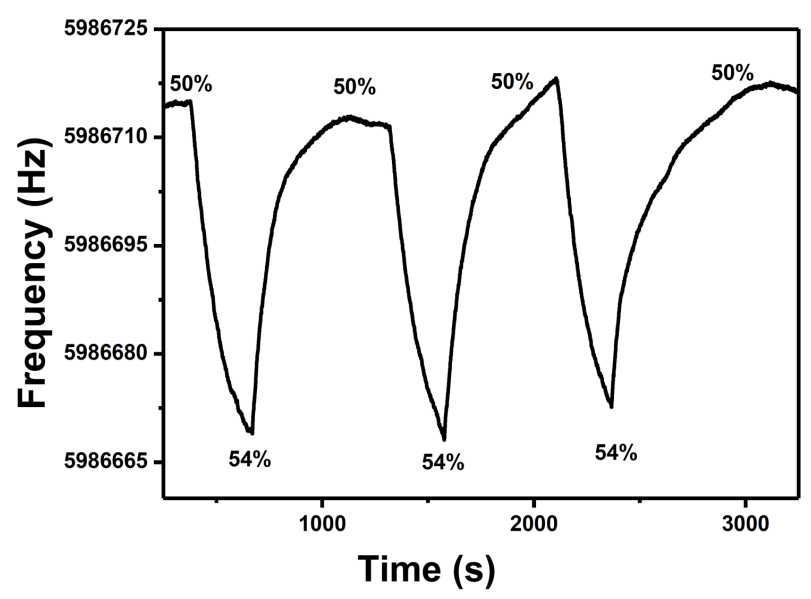

Fig. 7. Time dependent changes on the frequency of $\mathrm{ZnO}$ coated QCM sensor upon successive exposure cycles of $50 \%$ RH and $54 \%$. and 54\%. The sensor exhibits a highly sensitive and repeatable frequency response behavior towards humidity. The frequency shift is estimated as $46 \mathrm{~Hz}$. Comparing with frequency shift under ethanol and acetone, given us respectively $20,10 \mathrm{~Hz}$, it can be clearly seen that the shift is two orders greater. The response and recovery times are estimated as 294 and $155 \mathrm{~s}$.

Another important performance parameter of humidity sensors is hysteresis property which is determinated by measuring the steady state sensor using successive operation of injection humidity and dehydration of the sensor [25]. We illustrate in Fig. 8 the response of the uncoated QCM and $\mathrm{ZnO}$ coated QCM sensor in successive stepwise RH. It can be seen that the sensor has higher hysteresis humidity, compared to the uncoated commercial QCM.

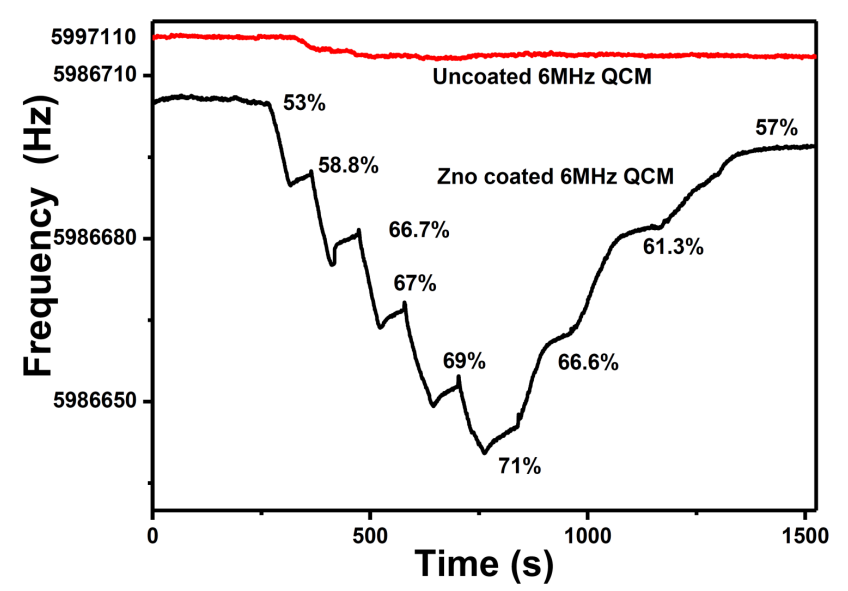

Fig. 8. Transient frequency responses of (a) uncoated $6 \mathrm{MHz}$ QCM, (b) $\mathrm{ZnO}$ coated $6 \mathrm{MHz}$ QCM.

\section{Conclusion}

In this paper, we presented fabrication of gas sensor based on $\mathrm{ZnO}$ thin films coated on commercial quartz crystal microbalance as humidity and volatile sensor using a simple dropping chemical method. We report that $\mathrm{ZnO}$ thin film was deposited on one side of quartz electrode at $T=350{ }^{\circ} \mathrm{C}$ in ambient air. X-ray diffraction and SEM images demonstrate that we obtained granular $\mathrm{ZnO}$ thin film. The sensing properties in presence of volatile compounds like acetone and ethanol showed that the sensor was sensitive to ethanol more than acetone. The reproducibility and sensitivity was given for three concentrations 200, 100, and $50 \mathrm{ppm}$, and the frequency shift was linear to the variation of concentrations.

The humidity effect was carried on for different RH. The results showed that the film exhibits a high sensitivity under humidity compared to both ethanol and acetone gases. 


\section{References}

[1] S. Arshad, M.M. Salleh, M. Yahaya, Solid State Sci. Technol. 16, 75 (2008).

[2] K.N. Chappanda, O. Shekhah, O. Yassine, S.P. Patole, M. Eddaoudi, K.N. Salama, Sens. Actuat. B Chem. 257, 609 (2018).

[3] J. Xie, H. Wang, M. Duan, J. Tang, J. Ceram. Soc. Jpn. 126, 34 (2018)

[4] J. Xie, H. Wang, X.X. Liu, M. Duan, J.L. Tang, Y.Y. Wang, RSC Adv. 7, 47099 (2017).

[5] Nguyen Van Quy, Vu Anh Minh, Nguyen Van Luan, et al., Sens. Actuat. B Chem. 153, 188 (2011).

[6] T. Ates, C. Tatar, F. Yakuphanoglu, Sens. Actuat. A Phys. 190, 153 (2013)

[7] S. Özturk, A. Kösemen, Z.A. Kösemen, N. Kilinç, Z.Z. Özturk, M. Penza, Sens. Actuat. B 222, 280 (2016).

[8] T. Ito, Y. Fujii, N. Yamanishi, N. Asai, T. Shimizu, S. Shingubara, Proced. Eng. 168, 411 (2016).

[9] M. Lim, S. Mills, B. Lee, V. Misra, IEEE Sens. J. 18, 3590 (2018).

[10] J. Nisar, Z. Topalian, A. De Sarkar, L. Österlund, R. Ahuja, ACS Appl. Mater. Interfaces 5, 8516 (2013).

[11] M. Procek, A. Stolarczyk, T. Pustelny, E. Maciak, Sensors 15, 9563 (2015).

[12] T. Addabbo, A. Fort, M. Mugnaini, V. Vignoli, A. Baldi, M. Bruzzi, IEEE Trans. Instrumentat Measur. 67, 722 (2017).
[13] C. Zhang, Y. Luo, J. Xu, M. Debliquy, Sens. Actuat. A Phys. 289, 118 (2019)

[14] A. Ashour, M.A. Kaid, N.Z. El-Sayed, A.A. Ibrahim, Appl. Surf. Sci. 252, 7844 (2006).

[15] Z. Yuan, H. Tai, X. Bao, C. Liu, Z. Ye, Y. Jiang, Mater. Lett. 174, 28 (2016).

[16] T. Ito, N. Yamanishi, T. Shimizu, S. Shingubara, Multidisciplin. Digital Publ. Inst. Proceed. 1, 397 (2017)

[17] P. Kulha, J. Kroutil, A. Laposa, V. Procházka, M. Husák, J. Electr. Eng. 67, 61 (2016).

[18] A. Erol, S. Okur, N. Yağmurcukardes, M. Arıkan, Sens. Actuat. B Chem. 152, 115 (2011).

[19] H. Jin, X. Tao, B. Feng, L. Yu, D. Wang, S. Dong, J. Luo, Vacuum 140, 101 (2017).

[20] P. Scherrer, Nachr. Ges. Wiss. Göttingen 2, 96 (1918).

[21] O. Lupan, T. Pauporté, L. Chow, B. Viana, F. Pellé, L.K. Ono, B. Roldan Cuenya, H. Heinrich, Appl. Surf. Sci. 256, 1895 (2010).

[22] Powder Diffraction File, Joint Committee on Powder Diffraction Standards, card no. 36-1451.

[23] C.P.L. Rubinger, C.R. Martins, M.A. De Paoli, R.M. Rubinger, Sens. Actuat. B Chem. 123, 42 (2007).

[24] W.F. Jiang, M. Jia, Y.S. Wang, L.Y. Li, X.J. Li, Thin Solid Films 517, 2994 (2009).

[25] S..D. Zor, H. Cankurtaran, Int. J. Electrochem. Sci. bf 11, 7976 (2016). 